УДК 658.26

Г. В. Лужанська ${ }^{凶}$, А. С. Денисова

Одеський національний політехнічний університет, пр. Шевченка, 1, Одеса, 65044, Україна

$\triangle$ e-mail: anuta.od@mail.ru

\title{
ДОСЛІДЖЕННЯ СИСТЕМ ТЕПЛОЛОКАЛІЗАЦІЇ ПОВІТРЯНО-ТЕПЛОВИМИ ЗАВІСАМИ
}

\begin{abstract}
Для локалізації проривів зовнішнього холодного повітря в опалювальні примішення застосовують повітряно-теплові завіси. Розглянуто систему локалізації теплоти, иляхом перекривання в перемежованому порядку повітророзподільного отвори повітряно-теплової завіси. Досліджено температурне поле, утвореного повітряного потоку при різних початкових температурах витікання та визначено енергоефективний температурний інтервал, при якому теплообмін з навколишнім середовищем мінімальний.
\end{abstract}

Ключові слова: Повітряно-теплова завіса; Плоский повітряний струмінь; Початкова температура витікання; Ефективний температурний інтервал.

\author{
А. В. Лужанская, А. Е. Денисова
}

Одесский национальный политехнический университет, пр. Шевченко, 1, Одеса, 65044, Украина

\section{ИССЛЕДОВАНИЕ СИСТЕМ ТЕПЛОЛОКАЛИЗАЦИИ ВОЗДУШНО-ТЕПЛОВЫМИ ЗАВЕСАМИ}

Для локализации прорывов наружного холодного воздуха в отапливаемые помещения применяют воздушно-тепловые завесы. Рассмотрена система локализации теплоты, путем перекрывания в перемежающем порядке воздухораспределительного отверстия воздушно-тепловой завесы. Исследовано температурное поле, образованного воздушного потока при различных начальных температурах истечения и определен энергоэффективный температурный интервал, при котором теплообмен с окружающей средой минимален.

Ключевые слова: Воздушно-тепловая завеса; Плоская воздушная струя; Начальная температура истечения; Эфрективный температурный интервал.

This work is licensed under the Creative Commons Attribution International License (CC BY). http://creativecommons.org/licenses/by/4.0

\section{I. ВСТУП}

Удосконалення енергозберігаючих технологій сучасних будівель і споруд, а також промислових об'єктів при прориві зовнішнього холодного повітря в опалювальні приміщення $є$ найважливішим аспектом теплозахисту будинків та споруд при улаштуванні повітряно-теплових завіс[1].

Нагріте в калориферах повітря по повітроводам подається в короб, розрахований як камера статичного тиску, встановлений по всій довжині зовнішнього отвору, і істикає 3 щілинного прямокутного отвору насадка. Повітророзподільний насадок призначений для формування та випуску рівномірного по висоті отвору воріт струменя повітря. Щілинний насадок складається 3 двох огороджувальних сталевих стінок, до яких приварені поперечні полиці, призначені для направлення струменя повітря перпендикулярно осі короба з метою створення рівномірного струменя [2]. Насадок має довжину $25 \mathrm{~cm}$ - частково розташований в коробі і частково зовні (в площині воріт). Перекри- ваємо в перемежованому порядку отвори між полиць насадка сталевими пластинами усередині короба впочатку витікання струменя.

У результаті плоскій струмінь розбивається на безліч плоских повітряних потоків, які при злитті утворюють єдиний повітряний потік, запобігаючи проникнення холодного повітря [3].

Метою роботи є дослідження ефективності розглянутої системи теплолокалізації повітрянотепловими завісами при використанні щілинного отвору, що перекривається в перемежованному порядку.

\section{II. РЕЗУЛЬТАТИ ДОСЛІДЖЕНЬ}

Процеси, що відбуваються в теплолокалізуючому пристрої з розривом плоского струменя, вказують, що характер руху єдиного повітряного потоку має складний багатоступінчастий характер.

Для визначення оптимальних технологічних i конструктивних параметрів повітророзподільного 
щілинного перемежованого отвору теплолокалізуючого пристрою [4] виконаний аналіз процесів, що відбуваються в ньому, з точки зору можливості їх адекватного математичного опису.

Для визначення надлишкових температур при злитті плоских повітряних струменів розрахункова формула базуються на наступних передумовах [5]:

- при взаємодії струменів кількість руху і кількість надлишкової теплоти в сумарному потоці залишається постійним;

- надлишкові температури в поперечному перерізі взаємодіючих струменів підкоряються універсальним залежностям для профілів температур вільних турбулентних струменів.

Тоді для паралельних плоских струменів однакової ширини $\mathrm{b}_{\mathrm{o}}$ залежность має вигляд:

$$
\frac{t_{x}}{t_{O}}=n k_{1} \sqrt{\frac{b_{o}}{x}},
$$

де $t_{\mathrm{o}}$ - початкова температура витікання, ${ }^{\circ} \mathrm{C}$; $t_{\mathrm{x}}-$ надмірна температура повітряного потоку, ${ }^{\circ} \mathrm{C} ; n$ - коефіцієнт зміни температури; $k_{1}$ - число груп струменів, осі яких розташовані на однаковій відстані до розглянутої точки; $b_{\text {о }}$ - ширина плоского струменя, м; $x-$ відстань по горизонталі від отвору витікання, м.

Таким чином, найбільш переважними для розрахунку процесів при витіканні повітряного струменя 3 повітророзподільного отвору повітряно-теплової завіси є використання системи рівнянь для універсального профілю температур [5], розв'язуваних методами чисельного моделювання.

Дослідження $з$ визначення температурних полів були розбиті на 3 етапи:

- дослідження ефективності роботи повітрянотеплової завіси при різних параметрах конструкції щілинного повітророзподільного отвору;

- визначення оптимальних параметрів температурних полів, утворених при взаємодії повітряних струменів;

- дослідження відносної температури, повітряного потоку, утвореного при взаємодії повітряних струменів.

Визначальними факторами, що впливають на ефективну роботу повітряно-теплових завіс, $є$ комплекс аеродинамічних параметрів (швидкість і температура витікання, геометричні розміри струменів і єдиного повітряного потоку, далекобійність потоку, відстань від місця витікання), дослідження яких в залежності від конструктивних параметрів можливо експериментальним шляхом для отримання кількісної моделі [4].

У результаті дослідження отримано графічні залежності.

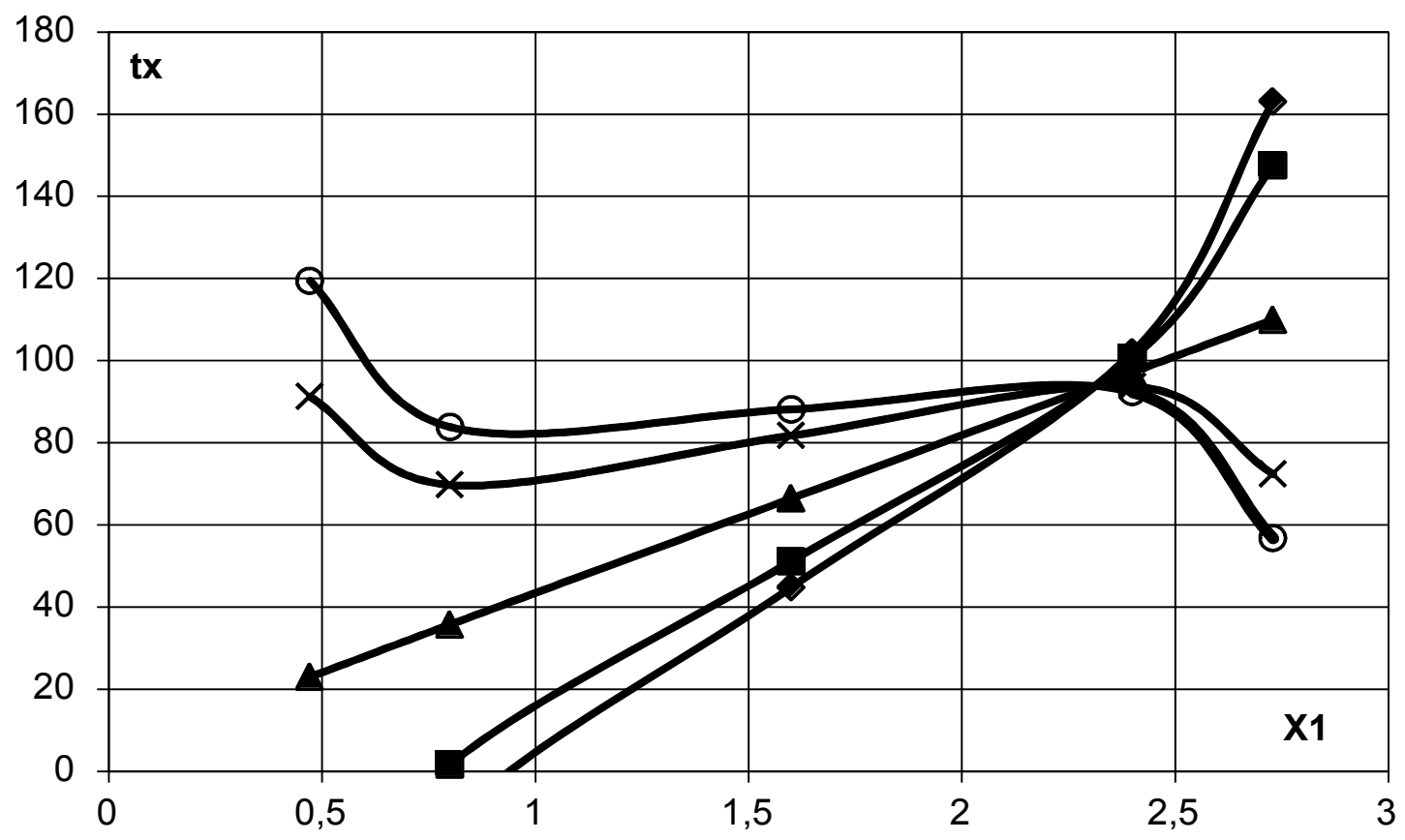

Рисунок 1 - Зміна надмірної температури повітряного потоку $t_{x}$ залежно від збільшення відстані по горизонталі (технологічного параметра х1):

- - початкова температура витікання $t_{o}=26^{\circ} \mathrm{C}$; $\mathbf{\square}-t_{o}=30^{\circ} \mathrm{C}$;

$\mathbf{\Delta}-t_{o}=40^{\circ} \mathrm{C} ; \mathbf{x}-t_{o}=50^{\circ} \mathrm{C} ; \mathbf{0}-t_{o}=56^{\circ} \mathrm{C}$.

3 графіків (рисунок 1) видно, що при низьких початкових температурах витікання $\left(26-36^{\circ} \mathrm{C}\right)$ сумарна температура повітряного потоку різко змінює своє значення в бік зменшення від місця витікання. При більш високих початкових температурах $\left(50-60^{\circ} \mathrm{C}\right)$ зміна температурного поля більш плавне, криві більш пологі. Точки злиття - критична точка, коли резуль- туюча температура на певній відстані незалежно від сторонніх факторів приймає одне значення. Це дозволяє зробити висновок, що температура витікання повинна бути в діапазоні $26-36^{\circ} \mathrm{C}$, тому із збільшенням температури витікання збільшуються теплообмінні процеси з навколишнім середовищем. 


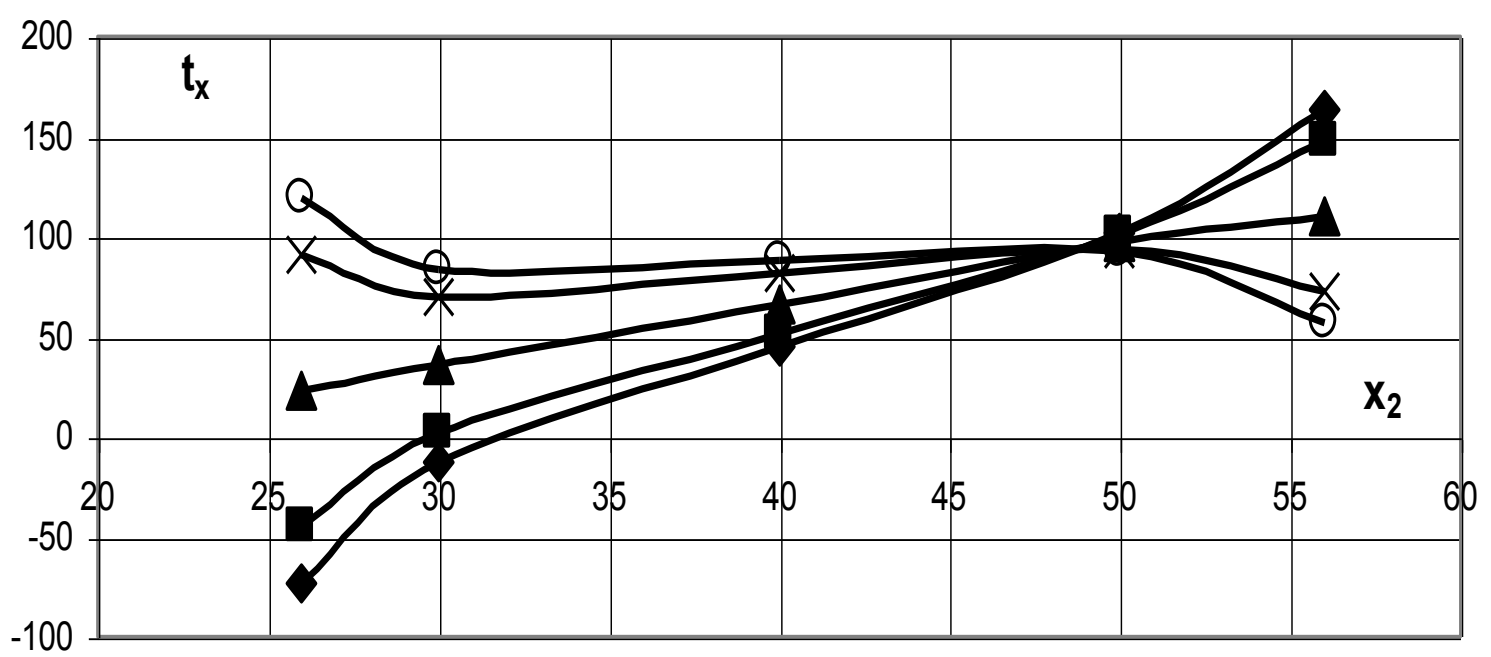

Рисунок 2 - Зміна надмірної температури повітряного потоку $t_{x}$ залежно від початкової температури витікання $t_{o}\left(x_{2}\right)$ при при постійній відстані від місия витікання:

$\bullet-x=0,472 \mu ; \mathbf{-}-x=0,8_{\mu ;}-x=1,6 \mu ; \mathbf{x}-x=2,4 \mu ; \mathbf{0}-x=2,73_{\mathcal{M}}$

Аналізуючи графіки (рисунок 2) видно, що зі збільшенням відстані кінцева температура менше залежить від початкової температури витікання. Ця залежність яскраво виражена на менших відстанях. Кри- тична точка - злиття всіх кривих, що пояснює, що результуюча температура злиття постійна для всіх первинних температур (ця величина в методиках розрахунку є нормованою) [5].

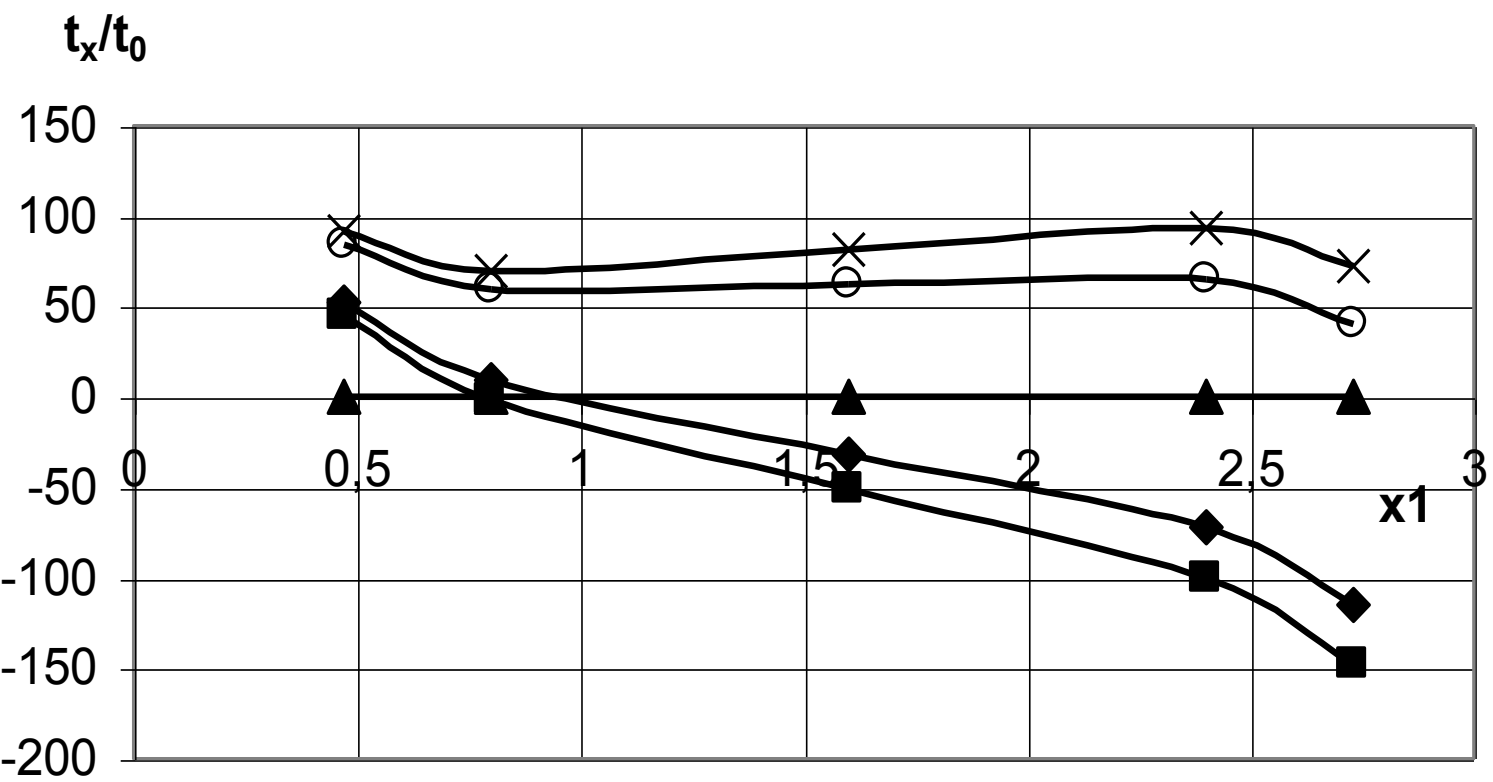

Рисунок 3 - Зміна надмірної температури повітряного потоку $t_{x} / t_{o}$ в залежності від збільшення відстані по горизонталі (технологічного параметра $x_{1}$ ):

- початкова температура витікання $t_{o}=26^{\circ} \mathrm{C}$; $\mathbf{\square}-t_{o}=30^{\circ} \mathrm{C} ; \boldsymbol{\Delta}-t_{o}=40^{\circ} \mathrm{C} ; \mathbf{x}-t_{o}=50^{\circ} \mathrm{C}$; $\mathbf{0}-t_{o}=56^{\circ} \mathrm{C}$

Криві (рисунок 3) відповідні великим температурам витікання $t_{\mathrm{o}}=50-60^{\circ} \mathrm{C}$ більш пологі, це пояснюється значним теплообміном з навколишнім середовищем і говорить про недоцільність застосування високих температур витікання.

Криві, що характеризують значення відносних температур при порівняно невеликих початкових те- мпературах $t_{\mathrm{o}}=26-36^{\circ} \mathrm{C}$ носять більш крутий характер. У результаті теплообмін з навколишнім середовищем незначний і втрачається менше тепла [5]. При нагріванні повітряної маси до даних початкових температур витікання відбувається економія теплової енергії. Визначений температурний інтервал є раціональним. 


\section{III. ВИСНОВКИ}

Отримані результати дослідження температурних полів, які утворюються шляхом злитті плоских повітряних потоків, витікаючих 3 повітророзподільного отвору повітряно-тепловий завіси, перекриваємого в перемежованому порядку, зазначили, що визначений інтервал початкових температур $t_{\mathrm{o}}=26-36^{\circ} \mathrm{C} \epsilon$ раціональним, в результаті теплообмін 3 навколишнім середовищем незначний.

\section{ЛІТЕРАТУРА}

1. Лужанская А. В. Энергосбережение в процессах локазизации прорывов воздуха в помещения через открытые проемы.//Тр. Одес. политехн. ун-та. - Одесса: ОНПУ. - 2002. - Вып. 2(18).- С. 68-70
2. Исаев В. Ф., Лужанская А. В. Ресурсосбережение В процессах теплоснабжения вентиляционноотопительных систем промышленных зданий. // Холодильна техніка і технологія. Одесса:- 2003. № 5(85). - C.51-54.

3. Исаев В. Ф., Лужанская А. В. Энергосберегающая функция воздушно-тепловых завес. // Вісник ОДАБА. - Одеса: ОДАБА. - 2005. - №17. - С. 97-99

4. Патент Украины UA 64378 A MKI F24F9/00. Способ создания воздушной завесы. /Лужанская А.В., Лужанская И.И. Заявл. 22.05.03; Опубл. 16.02.04, Бюл. №2., $2004-2$ c.

5. Лужанская А. В., Зайщев О.Н., Аэродинамика воздушно-тепловых завес в промышленных зданиях и сооружениях (монография). Научное издание к 50-ти летию НАПКС - Симферополь: НАПКС, СОНАТ 2009 -184, ISBN 9668111-56-7

Отримана в редакції 11.10.2016, прийнята до друку 01.11.2016

\section{G. V. Luzhanska ${ }^{凶}$, A. E. Denysova}

Odessa National Polytechnic University, 1 Shevchenko av., Odessa, 65044, Ukraine

$\bowtie$ e-mail: anuta.od@mail.ru

\section{STUDY OF HEAT LOCALIZATION SYSTEMS BY USING AIR-THERMAL CURTAINS}

Enormous masses of cold air come into the warm rooms through the outer apertures in cold period of year. That's why the substantial expenditure of thermal energy for heating is necessary for ensuring the normal internal microclimate. Air curtains are used for prevention of external cold air flow breakthrough into warm rooms according to energy-saving technologies requirements. The proposed system of heat localization consists of heat air curtains, where the airflow from the narrow gap nozzles, by overlapping vertically in interleaved order is organized, and then merging into a single flow at the initial part, preventing the penetration of cold air. The determining factor influencing on efficient operation of the air curtains, is a complex of aerodynamic parameters such as speed, temperature of airflow, as well as geometric dimensions of single jet and common airflow, long range of flow and distance of airflow entrance. The research was aimed at identifying of optimum temperature of air flow and was carried out in several stages: studies of air curtains efficiency for various geometric dimensions of gap nozzles; determination of temperature optimal distribution while air jets interaction; study of the relative temperature of common airflow formed by air jets interaction. As a result the graphs were obtained. It was revealed that with increasing of distance the final temperature of steam is less dependent of airflow initial temperature. As a result the effective temperature range of the initial expiration, when the heat exchange with the environment is negligible was determined, and the most effective work mode of thermal air curtains was obtained.

Keywords: Air-thermal curtain; Flat air jet; Initial temperature of expiration; Energy-efficient temperature range.

\section{REFERENCES}

1. Luzhanskaya, A. V. (2002). Energysaving in the process of localizing the air inrushes indoors through openings. Trudy Odesskogo polytechnicheskogo universiteta. ONPU, 2(18), 68-70 (in Russian). URL: http://storage.library.opu.ua/online/periodic/opu_2002_2 $\% 2818 \% 29 /$ index.htm

2. Isaev, V. F., Luzhanskaya, A. V. (2003). Saving of resourcesduring heat supply of ventilating and heating systems in industrial buildings. Refrigeration Engineering and Technology, no. 5 (85), 51-54 (in Russian).
3. Isaev, V. F., Luzhanska, G. V. (2005). Energosberegaushchaia funktsiia vozdushno-teplovikh zaves. Odessa. ODABA, (17), 97-99 (in Russian).

4. Patent of Ukraine UA 64378 A MKI F24F9/00 Luzhanska, G. V., Luzhanska, I. I. Sposob sozdania vozdushnoi zavesy, 2004.

5. Luzhanska G. V., Zaicev O. N. (2009). Aerodinamika vozdushno-teplovykh zaves $v$ promishlennykh zdaniakh i sooruzheniakh (monografia), 184 p. (in Russian). 